\title{
Corrosion Behavior of Fe-Al-Zn Interphased Dual Phase Steel in Marine Environment
}

\author{
Itopa Monday Momoh*, Isaac Enesi Dongo \\ Department of Metallurgical and Materials Engineering, Kogi State Polytechnic, Lokoja, Nigeria \\ Email: *rhodave2011@gmail.com
}

How to cite this paper: Momoh, I.M. and Dongo, I.E. (2019) Corrosion Behavior of Fe-Al-Zn Interphased Dual Phase Steel in Marine Environment. Journal of Minerals and Materials Characterization and Engineering, 7, 71-79.

https://doi.org/10.4236/jmmce.2019.72006

Received: January 1, 2019

Accepted: March 15, 2019

Published: March 18, 2019

Copyright $\odot 2019$ by author(s) and Scientific Research Publishing Inc. This work is licensed under the Creative Commons Attribution International License (CC BY 4.0).

http://creativecommons.org/licenses/by/4.0/

\begin{abstract}
Intercritical heat treatment operation has been in use for the development of Dual Phase Steel (DPS) and has been found to improve the mechanical properties of the steel. In spite of the enhancement a limitation was however observed as to its corrosion susceptibility. In a bid to further enhance the corrosion resistance of the DPS while maintaining its mechanical properties, galvanealing operation was adopted which involving the immersion of the DPS into Al-Zn melt and subsequently subjecting it to annealing operation at $550^{\circ} \mathrm{C}$. Weight loss and linear polarization technique were used to measure or evaluate its resistance in $3.5 \% \mathrm{NaCl}$ (a simulated marine environment). A minimum of 3 samples was used per immersion time. From the result, it was observed that there is a general sharp decrease in the corrosion rate of the GAS as compared to the control sample. The sample immersed and allowed to dwell in the melt for 20 seconds and further annealed with a soaking time of 20 minutes exhibited the highest corrosion resistance. The polarization curve also shows that the substrate was generally passivated, and this is as a result of the $\mathrm{Al}-\mathrm{Zn} / \mathrm{Fe}$ adhesiveness.
\end{abstract}

\section{Keywords}

Ternary Phase, Dual Phase Steel, Galvanealed Steel, Linear Polarization Curve

\section{Introduction}

Galvaneal as a process is the result of the combined process of galvanizing and annealing to produce specialized steel substrate. The galvanization is made through the conventional hot-dipping process; and immediately as the stripe exits the coating, the zinc coating is subject to an in-line heat treatment that converts the entire coating to a zinc iron alloy [1]. Galvaneal does not flake of its galvanized coating when formed, stamped, and bent. The very fine matte finish 
acts like a primer, allowing paint to adhere easily, and is very rust proof; only white to dark grey marks appear if it comes in contact with water.

Conversion to the alloy results in a non-spangle finish which makes the sheet suitable for painting after fabrication [2]. This research is to generate a high adhesive $\mathrm{Fe}-\mathrm{Al}-\mathrm{Zn}$ ternary structure intermetallic compound on the corrosion resistance and investigate the feasibility and reliability of indigenous produced low carbon steel. It has been observed that galvanealed steel exhibited excellent durability despite the harsh industrial and coastal environment or $\mathrm{pH}$ environment; this is due to its high resistance to corrosion. In spite of these benefits, it has been a challenge to apply this technique to structural steel (e.g. medium carbon steel). As an alternative, however, dual phase steel (DPS) has been observed to possess combined mechanical and corrosion properties suitable for structural applications.

DPS has found thorough applications in automotive industries where low carbon steel has been processed to yield high strength to weight ratio [3]. Recently however, some researchers are delving into developing dual phase steel structures for structural applications [4] [5] [6]. Low carbon steel has been the conventional steel in use for the hotdip galvanizing technology. This steel is always accompanied by lean alloy chemistry that could enhance the adherence between the coatings and the steel surface. No report on the development of galvanneal steel using dual phase medium carbon low alloy steels as a source. This could be due to a great extent on the complex nature of the transformation processes occurring during treatment of steels of medium carbon composition in the $(\alpha+\gamma)$ phase region. This has made it difficult to optimize the process variables and potential engineering properties that can be harnessed from the intercritical treatment [7] [8]. The use of medium carbon steel with optimum combined mechanical and corrosion properties serves as an impetus to these study of adopting the galvanneal intercritical techniques in the production of high strength, high corrosion resistance medium carbon steel.

In the quest for development of steel based materials for applications where high strength, ductility and corrosion are required, a lot of researches have been carried out on low carbon steel with lean alloying elements. This has led to the development of galvanneal steel strip/sheets. The steel compositions conventionally utilized for these purposes are low carbon microalloy steel (high strength low alloy steels) [3] [9].

In the low carbon microalloy steel, the influence of process parameters on the adherence of the coating elements to enhance the corrosion properties has been well documented. Reumont and associate [10] studied the mechanical behavior of galvanized, interstitial free steel in air and sodium chloride water and found that while the ductility was not hampered, hydrogen embrittlement was observed which lead to corrosion of the coated material. In 2000, Kato [11] studied the reactions between molten $\mathrm{Zn}$ and Fe directly by means of in in-situ heating experiment in a highvoltage electron microscope and from his observation definitely shows that the Al depletion and other models there attached model is of 
doubtful validity. Long [12] studied the morphology and microstructure of galvanneal coating of both stamped and uniform steel sheet and found that the frequency of defects in stamped components was found to be related to the average alloy content in the coatings, which varied with furnace temperature. An increased average iron content in the coatings was related to increased powdering defects in stamping operations that use galvanneal coated sheet steel.

Many other authors have contributed through their findings to a greater understanding and application of galvanneal steel production but none has been reported on the use of medium carbon steel for structural application. This is due to a great extent on the complex nature of the transformation processes occurring during treatment of steels of medium carbon composition in the $(\alpha+\gamma)$ phase region.

This research will focus on a comprehensive study of the transformation behavior of the structural steel in the dual phase region with a view to establishing optimum conditions for the production of a well defined galvanneal medium carbon with dual phase microstructures as reference.

\section{Materials and Method}

\subsection{Materials and Equipments}

Materials used for the construction of ship are stored at the dockyard, and from there, steel sample was selected for this experiment. The selected steel was firstly sparked with argon gas using spectrophotometric analyzer to determine the chemistry of the steel. The chemical composition is shown in Table 1 . In the same vein, the chemical composition of 6063 Aluminum scrap was also determined and here shown in Table 2. Zinc granules were also procured for the hot-dipping processes.

Some of the equipments used in the course of this experiment include:

- Hacksaw, Bench vice: This was used to clamp and cut the steel to predetermined sizes.

- Muffle furnace: This served dual purpose in the experiment. Firstly, it was used in the melting of the aluminum and zinc to form Al- $\mathrm{Zn}$ melt into which the steel sample was immersed for coating; and secondly, it serves in the immediate subsequent annealing operation.

Table 1. Chemical composition of the selected medium carbon steel.

\begin{tabular}{cccccccccc}
\hline Element (wt\%) & $\mathbf{C}$ & $\mathrm{Si}$ & $\mathrm{S}$ & $\mathbf{P}$ & $\mathrm{Mn}$ & $\mathrm{Ni}$ & $\mathrm{Mo}$ & $\mathrm{V}$ & $\mathrm{Cu}$ \\
\hline Composition & 0.3007 & 0.1029 & 0.0064 & 0.0352 & 0.8022 & 0.1120 & 0.0095 & 0.0046 & 0.4605 \\
Elements (wt\%) & $\mathrm{W}$ & $\mathrm{As}$ & $\mathrm{Sn}$ & $\mathrm{Co}$ & $\mathrm{Al}$ & $\mathrm{Pb}$ & $\mathrm{Zn}$ & $\mathrm{Fe}$ & \\
Composition & 0.0022 & 0.0114 & 0.0083 & 0.0089 & 0.0037 & 0.0061 & 0.0045 & Bal. \\
\hline
\end{tabular}

Table 2. Chemical composition of the selected aluminum ingot.

\begin{tabular}{cccccccccc}
\hline Element (wt\%) & $\mathrm{Si}$ & $\mathrm{Fe}$ & $\mathrm{Cu}$ & $\mathrm{Mn}$ & $\mathrm{Mg}$ & $\mathrm{Cr}$ & $\mathrm{Ti}$ & $\mathrm{Ca}$ & $\mathrm{Al}$ \\
\hline Composition & 0.4430 & 0.1638 & 0.0041 & 0.0132 & 0.5835 & 0.0024 & 0.0078 & 0.0002 & 98.751
\end{tabular}


- Tong: this aids both the immersion and easy transportation of the samples at high temperature.

- Optical Microscope: This was used in viewing the microstructures of the developed galvannealed steel (GA Steel) prior to analysis, this is essential in order to study the developed structure and the interphase form.

\subsection{Methodology}

- Sample preparation: The sample was prepared by sourcing for steel scraps used in the ship dockyard, Lagos and it was machine into a corrosion coupon using hack saw and emery paper on a grinding machine. The grinding was done simultaneously alongside using water as coolant in order to avoid phase transformation of the steel which could ensue from the friction between the sample and the emery grits. The zinc and aluminum were also cut and measured to weight using weighing balance calibrated to 2 decimal places for high accuracy. Grinding of the steel surface was necessary to enhance its adhesiveness during coating.

- Melting and immersion: $99.7 \%$ zinc was melted in $0.3 \%$ aluminum at $664^{\circ} \mathrm{C}$ in a sequential order of the aluminum preceding zinc. The binary melt was held in the furnace to maintain its state. Hot-dipping was later adopted by immersing the prepared steel into the binary melt and allowed to soak for varied times of 5, 10, 15 and 20 seconds. This is to enhance thorough adhesiveness of the melt on the substrate which has been pre-heated at $400^{\circ} \mathrm{C}$. The immersed samples were immediately transferred to another muffle furnace maintained at $550^{\circ} \mathrm{C}$ and allowed to soaked again for 10,20 , and 30 minutes. Four samples were used per treatment for both the microstructural and corrosion tests to be conducted.

- Corrosion: The corrosion process of a galvannealed coating layer was done by making a solution of $3.5 \mathrm{wt} \% \mathrm{NaCl}$ solution. The weight was measured at a regular interval of 3 days, before calculating the metal and the corrosion rate of the samples using the formula adapted from ASTM G1-G4 standard.

$$
\begin{gathered}
\text { metal Loss }=\frac{\text { weight } \operatorname{Loss}(g) \times K}{\text { alloy Density }\left(\mathrm{cm}^{-3}\right) \times \operatorname{exposed} \operatorname{Area}(A)} \\
\text { Corrosion Rate }=\frac{\text { Weight Loss }(g) \times K}{\text { Alloy Density }\left(\mathrm{cm}^{-3}\right) \times \operatorname{Exposed} \operatorname{Area}(A) \times \operatorname{Exposure~Time~}(h r)}
\end{gathered}
$$

Polarization Measurement: The AutolabPotentiostat with Nova 2.0 software and with a potential of $-0.2 \mathrm{mv}$ to $1.2 \mathrm{mv}$ at a scan rate of $0.01 \mathrm{mv}$ was used to determine the polarization of the test sample in the solution using platinum counter electrode. The Autolabpotentiostat after carrying a Linear Voltammetry sweep test on the steel samples in different varying environments analyzed and recorded the corrosion parameters, such as the Icorr in area per centimeter square, Ecorr, in voltage and the corrosion rate in millimeter per year among other parameters. 


\section{Results and Discussion}

Intercritical heat treatment operation, when carried out on mild steel, has been found to enhance the hardness and strength with reasonable ductility in comparison to other conventional heat treatment [5]. In spite of these findings, its application in corrosion prone environment have been of concern especially in marine environment. The process of gavanealing has currently contributed to the uniquely high corrosion resistance these steel in simulated marine environment. The findings in Figures 1-3 testify to these claims.

Figure 1 shows the response of GAS in $3.5 \% \mathrm{NaCl}$. It is clearly observed that the rate of corrosion of GAS decreases with annealing time. This trend is as a result of the adhesive interphase between $\mathrm{Al}-\mathrm{Zn}$ and the Fe-substrate, the bond gets more strength as the temperature increases, thus leading to the passivation of the substrate and reducing the corrosion rate to as low as $0.4 \mathrm{~mm} / \mathrm{yr}$.

When the DPS was immersed with a dwell time of 10 seconds prior to annealing (see Figure 1(b)), a different trend was observed. Little difference was displayed between the treated steel and the control sample with negligible range value of $0.5760 \mathrm{~mm} / \mathrm{yr}$ as compared to the previous with a range value of about $1.0 \mathrm{~mm} / \mathrm{yr}$.

A reverse trend was however observed in Figure 1(c) where the samples were allowed to dwell in the $\mathrm{Al}-\mathrm{Zn}$ melt for 15 seconds prior to annealing. At 10 minute annealing time, the lowest corrosion rate of $0.6183 \mathrm{~mm} / \mathrm{yr}$ was observed which gradually increased to $0.8911 \mathrm{~mm} / \mathrm{yr}$ as the samples were allowed to soak for 30 minutes in the furnace.

This unusual gradual rise could be attributed to the formation of cracks ensued from the heterogeneity of the melt before annealing.

Figure 1(d) displays the best corrosion resistance of the GAS as it possesses the least corrosion rate value of $0.3487 \mathrm{~mm} / \mathrm{yr}$ with a very wide and appreciative margin of $1.0744 \mathrm{~mm} / \mathrm{yr}$ as compared to the control sample. Thus, this sample and treatment generally has the lowest corrosion rate and thus the highest resistance to corrosion in marine environment (see Figure 2).

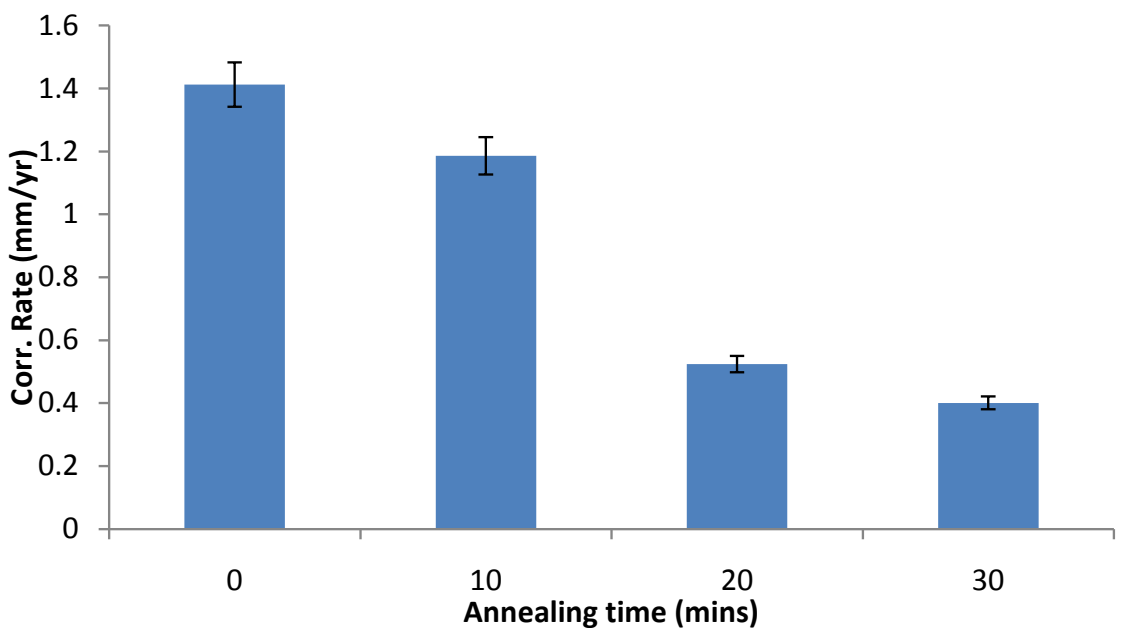

(a) 


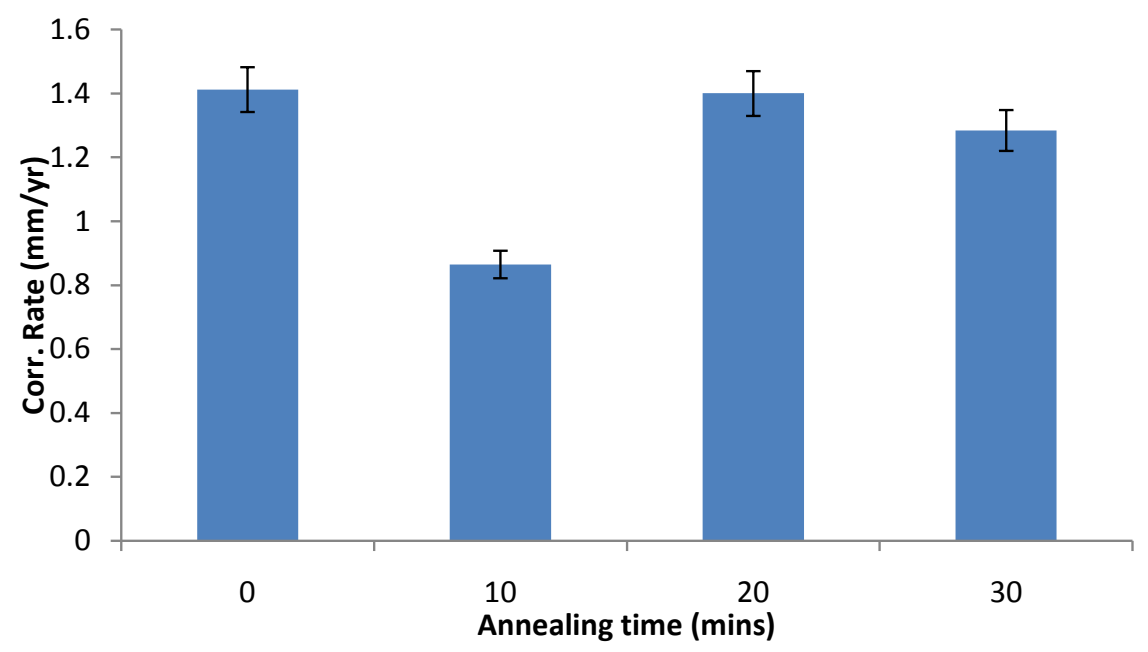

(b)

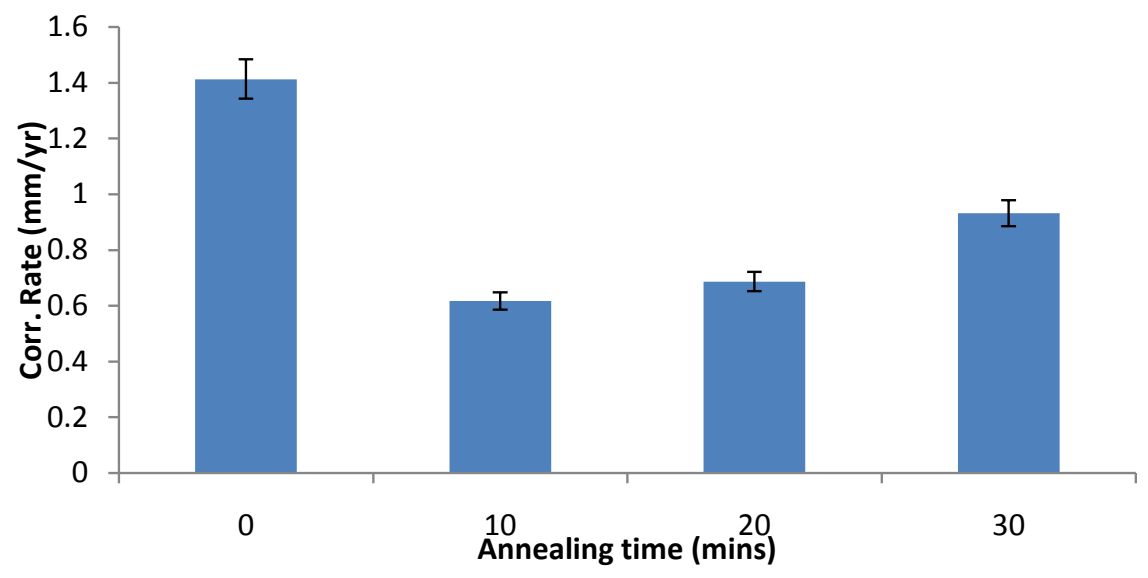

(c)

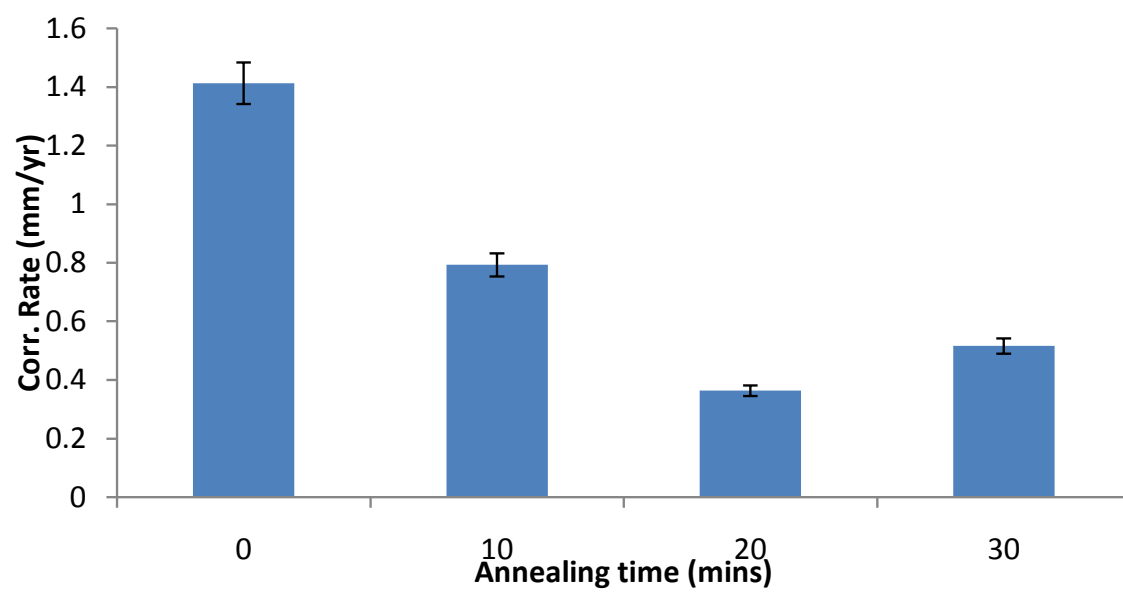

(d)

Figure 1. (a) Response of GAS-5 in marine environment; (b) Response of GAS-10 in marine environment; (c) Response of GAS-15 in marine environment; (d) Response of GAS-20 in marine environment.

Linear polarization curve technique as shown in Figure 3 was also used to evaluate and justify the weight loss approach of corrosion investigation. The 


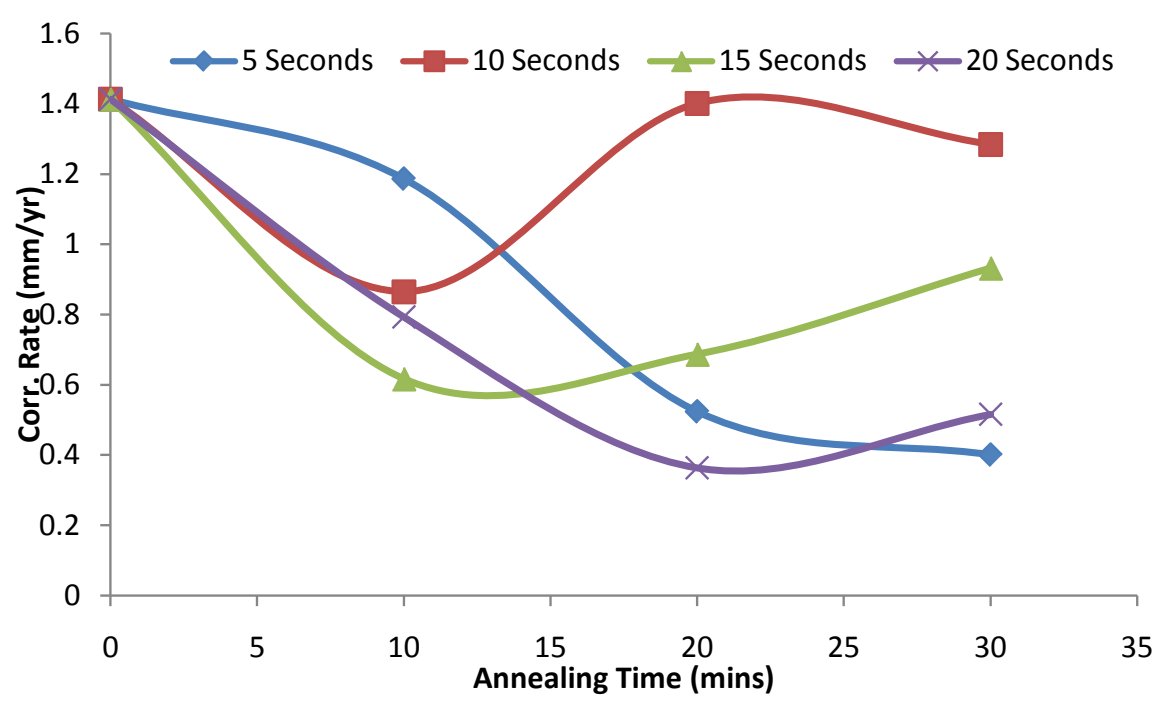

Figure 2. Comparative responses of GAS in marine environment.

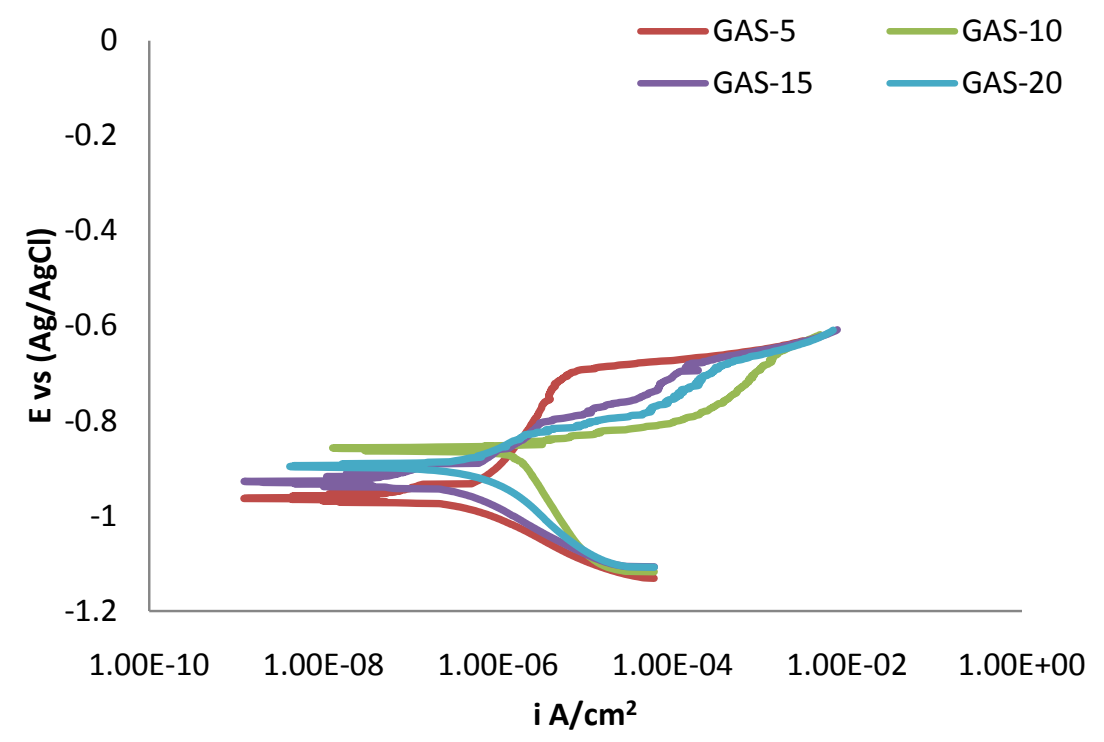

Figure 3. Linear polarization curve of GAS in marine environment.

polarization curves indicated that both anodic and cathodic reactions are passivated as a result of the adhesiveness between $\mathrm{Al}-\mathrm{Zn} / \mathrm{Fe}$-substrate and the inherent corrosion resistance property of the $\mathrm{Al}-\mathrm{Zn}$.

\section{Conclusions}

In a bid to improve on the corrosion resistance of Dual Phase Steel (DPS) in marine environment, intercritical heat treatment technique was adopted for the development of the steel and further subjected to galvanealing operation.

Weight loss and linear polarization methods were used to evaluate the corrosion behavior. From the result, the following was observed:

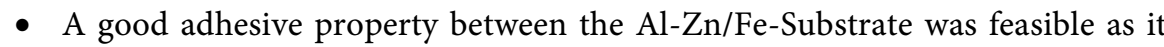
contributes to the enhanced resistance recorded. 
- Corrosion rate of as low as $0.3 \mathrm{~mm} / \mathrm{yr}$ was observed in comparison to the control sample which displays about $1.4 \mathrm{~mm} / \mathrm{yr}$ rate.

- Galvanealing operation did successfully shift the steel from corrosion to passivation region thus improving the activity life of the GAS when in use.

Thus, dual phase galvanealed steel (DP-GAS) is recommended for use in marine environment due to its unique combined mechanical properties and the current finding of improved corrosion resistance.

\section{Acknowledgements}

The authors of this article heartily appreciate the management of Tertiary Education Trust Fund (TET Fund) for sponsoring this research and to the management of Kogi State Polytechnic, Nigeria for their support.

\section{Conflicts of Interest}

The authors declare no conflicts of interest regarding the publication of this paper.

\section{References}

[1] Alaneme, K.K. (2010) Influence of Tempered Microstructures on the Transformation Behaviour of Cold Deformed and Intercritically Annealed Medium Carbon Low Alloy Steel. Materials Research, 13, 203-209. https://doi.org/10.1590/S1516-14392010000200014

[2] Alaneme, K.K., Adejumo, O.J. and Borode, J.O. (2013) Influence of Different Cyclic Intercritical Heat Treatment Schedules on the Microstructure and Mechanical Behaviour of a Dual Phase Medium Carbon Low Alloy Steel. Association of Metallurgical Engineers of Serbia, Metallurgical and Materials Engineering, 19, 155-165.

[3] Dongsheng, L., Matthias, M. and Warren, P. (2007) Microstructure Model for a Dual-Phase Steel. Material Science Forum, 539-543, 4391-4396. https://doi.org/10.4028/www.scientific.net/MSF.539-543.4391

[4] Hambidge, K.M. and Krebs, N.F. (2007) Zinc Deficiency: A Special Challenge. Journal of Nutrition, 137, 1101-1105. https://doi.org/10.1093/jn/137.4.1101

[5] Holm, E.A., Miodownik, M.A. and Rollet, A.D. (2003) On Abnormal Subgrain Growth and the Origin of Recrystallization Nuclei. Acta Materialia, 51, 2701-2716. https://doi.org/10.1016/S1359-6454(03)00079-X

[6] Kato, T., Nunome, K., Morimoto, Y., Nishimura, K. and Saka, H. (2000) In-Situ High-Voltage Electron Microscopy Observation of Reactions between Molten Zn and Fe. Philosophical Magazine Letters, 80, 54-57. https://doi.org/10.1080/095008300176146

[7] Long, J.M., Haynes, D.A. and Hodgson, P.D. (2004) Characterization of Galvanneal Coating on Strip Steel. Materials Forum, 27, 62-67.

[8] Momoh, I.M. (2012) Microstructures, Corrosion and Mechanical Behavior of Dual Phase Medium Carbon Low Allow Steels. MSc Thesis, Department of Metallurgical and Materials Engineering, The Federal University of Technology, Akure, Nigeria. $1-5$.

[9] Sepper, S., Peetsalu, P. and Saarna, M. (2011) Methods for Evaluating the Appearance of Hot Dip Galvanized Coatings. Agronomy Research, 9, 229-236. 
[10] Reumont, G., Vogt, J.B., Iost, A. and Foct, J. (2001) The Effects of an Fe-Zn Intermetallic-Containing Coating on the Stress Corrosion Cracking Behavior of a Hot-Dip Galvanized Steel. Surface and Coatings Technology, 139, 265-271. https://doi.org/10.1016/S0257-8972(01)01017-9

[11] Yang, J.R. and Chen, L. (1991) Dual Ferrite-Martensite Treatment of a High Strength Low Alloy ASTM A588 Steel. Material Science, 26, 889-898. https://doi.org/10.1007/BF00576764

[12] Zeytin, H.K., Kubilay, C. and Aydin, H. (2008) Investigation of Dual Phase Transformation of Commercial Low Alloy Steels: Effect of Holding Time at Low Intercritical Annealing Temperatures. Materials Letters, 62, 2651-2653.

https://doi.org/10.1016/j.matlet.2008.01.037 